\title{
NICKEL SOLUBILITY AND PRECIPITATION IN SOILS: A THERMODYNAMIC STUDY
}

\author{
Edward Peltier ${ }^{1, *}{ }^{+\dagger}$, Ramakumar Allada ${ }^{2,+}$, Alexandra Navrotsky $^{2}$ and Donald L. Sparks ${ }^{1}$ \\ ${ }^{1}$ Environmental Soil Chemistry Research Group, Department of Plant and Soil Sciences, 152 Townsend Hall, \\ University of Delaware, Newark, DE 19717-1303, USA \\ 2 Thermochemistry Facility, Department of Chemical Engineering and Materials Science, University of California, Davis, \\ CA 95616, USA
}

\begin{abstract}
The formation of mixed-metal-Al layered double hydroxide (LDH) phases similar to hydrotalcite has been identified as a significant mechanism for immobilization of trace metals in some environmental systems. These precipitate phases become increasingly stable as they age, and their formation may therefore be an important pathway for sequestration of toxic metals in contaminated soils. However, the lack of thermodynamic data for $\mathrm{LDH}$ phases makes it difficult to model their behavior in natural systems. In this work, enthalpies of formation for $\mathrm{Ni} \mathrm{LDH}$ phases with nitrate and sulfate interlayers were determined and compared to recently published data on carbonate interlayer LDHs. Differences in the identity of the anion interlayer resulted in substantial changes in the enthalpies of formation of the LDH phases, in the order of increasing enthalpy carbonate $<$ sulfate $<$ nitrate. Substitution of silica for carbonate resulted in an even more exothermic enthalpy of formation, confirming that silica substitution increases the stability of LDH precipitates. Both mechanical mixture and solid-solution models could be used to predict the thermodynamic properties of the LDH phases. Modeling results based on these thermodynamic data indicated that the formation of LDH phases on soil mineral substrates decreased Ni solubility compared to $\mathrm{Ni}(\mathrm{OH})_{2}$ over $\mathrm{pH} \mathrm{5-9}$ when soluble $\mathrm{Al}$ is present in the soil substrate. Over time, both of these precipitate phases will transform to more stable Ni phyllosilicates.
\end{abstract}

Key Words-Aqueous Solubilities, Calorimetry, Enthalpy of Formation, Layered Double Hydroxides, Ni Precipitation.

\section{INTRODUCTION}

Sorption reactions at mineral/surface interfaces play a dominant role in determining trace metal mobility, toxicity and bioavailability in soils. While some adsorption reactions are easily reversible, the formation of surface precipitate phases may result in permanent sequestration of trace metals into relatively bio-unavailable phases, thereby significantly reducing their impact on the surrounding environment. In recent years, several studies have suggested that the formation of surface precipitate phases may occur at similar timescales to adsorption reactions (Scheidegger et al., 1998), and thus have the potential to play a significant role in removing metal ions from solution. In order to accurately model and predict metal speciation in contaminated soils, therefore, it is important to determine both the fundamental properties of these phases and the conditions that allow for their formation in the environment.

Multiple studies have identified the formation of mixed metal-Al hydroxide phases as a significant uptake

* E-mail address of corresponding author: epeltier@udel.edu

† Present address: The University of Kansas CEAE Department, 1530 W 15 th Street, Lawrence, KS 66045-7609, USA

* Present address: Mail Code ES4, NASA Johnson Space Center, Houston, TX 77058, USA

DOI: $10.1346 /$ CCMN.2006.0540202 route for trace metals (including $\mathrm{Cr}, \mathrm{Co}, \mathrm{Ni}$ and $\mathrm{Zn}$ ) in environmental systems (Ford and Sparks, 2000; O'Day et al., 1994; Roberts et al., 2003; Scheidegger et al., 1997; Thompson et al., 1999b; Towle et al., 1997). These precipitates have a structure similar to that of hydrotalcite, with substrate-derived $\mathrm{Al}$ substituting into the octahedral sheet. The resulting net positive charge is compensated for by layers of hydrated anions that form between the hydroxide sheets. For this reason, these phases are often referred to as layered double hydroxides, or LDHs. Formation of these precipitates occurs at $\mathrm{pHs}$ undersaturated with respect to pure metal hydroxide solubility and at surface loadings below monolayer coverage. For Ni, in particular, these LDH phases form rapidly on pure substrates such as pyrophyllite, kaolinite and gibbsite at $\mathrm{pH}$ values $\geqslant 7$. Similar experiments on montmorillonite and vermiculite, however, resulted in the formation of other, non-LDH type precipitates, including $\mathrm{Ni}$ phyllosilicates and/or $\alpha$ $\mathrm{Ni}(\mathrm{OH})_{2}$ (Dähn et al., 2002; Scheinost and Sparks, 2000).

A significant property of these Ni-LDH surface precipitates is increased $\mathrm{Ni}$ retention as the precipitates age. Several studies document that, as LDH-type precipitates formed on pyrophyllite age, Ni release is greatly reduced (Scheckel et al., 2000; Scheckel and Sparks, 2001). With increased ageing the mixed Ni-Al surface precipitate on the pyrophyllite surface was 
transformed to a precursor mixed $\mathrm{Ni}-\mathrm{Al}$ phyllosilicate surface precipitate phase, thus enhancing Ni stability. The increased stability is due to a combination of factors, including both enhanced silicification of the anion interlayers and possible Ostwald ripening. Ford et al. (1999) used thermogravimetric analysis to confirm that, as the precipitates aged, there was exchange of the nitrate interlayer with silica originating from the pyrophyllite substrate. Similar silica exchange for carbonate interlayers over time has been observed for aged cobalt LDH phases (Thompson et al., 1999a) exposed to solution-phase silica. Based on this increased stability, it is possible that formation of these mixed metal-Al hydroxides could provide an important pathway for sequestration of toxic metals in contaminated soils.

At present, however, there are few available thermodynamic data for LDH phases, making it difficult to model their behavior in natural systems. After reviewing the available thermodynamic data for $\mathrm{Ni}$ in aqueous systems, Hummel and Curti (2003) concluded that LDH phases could dominate solid-phase $\mathrm{Ni}$ speciation at ambient conditions, but they did not have direct thermodynamic data for these phases. Johnson and Glasser (2003) determined $K_{\mathrm{sp}}$ values for $\mathrm{Mg}, \mathrm{Zn}$, Co and $\mathrm{Ni}$ LDH phases based on solubility measurements, but did not determine solid-phase enthalpies. Allada et al. (2002) compared measured enthalpies of several CoAl carbonate $\mathrm{LDH}$ phases to estimated values calculated from equivalent mechanical mixtures of binary hydroxides and carbonates, and obtained good agreement between the two approaches, with differences of $<10 \mathrm{~kJ} / \mathrm{mol}$. Similar work on Mg-Al LDH phases also suggested that solution $\mathrm{pH}$ and the ratio of $\mathrm{Al}$ to divalent metal ion activity, rather than thermodynamic preference, probably control the extent of Al substitution into the LDH structure (Allada et al., 2005). The effect of substituting other anions for carbonate in the interlayer on LDH precipitate enthalpy, however, was not determined in these experiments.

In this study, we determined the enthalpies of formation for $\mathrm{Ni} \mathrm{LDH}$ phases with $\mathrm{NO}_{3}^{-}$and $\mathrm{SO}_{4}^{2-}$ interlayers under several different formation conditions and compared these results to those published recently for carbonate interlayer $\mathrm{LDH}$ phases containing $\mathrm{Ni}$ and Co (Allada et al., 2006). These data were also used to further evaluate the usefulness of mechanical mixing models in predicting LDH enthalpies of formation, as suggested in several recent papers (Allada et al., 2002; Bravo-Suárez et al., 2004b). From the enthalpies of formation, we calculated solubility product constants for $\mathrm{Ni}$ LDH phases with carbonate, sulfate and nitrate interlayers and used these results to model the formation of $\mathrm{Ni}$ surface precipitates on mineral substrates of environmental importance. In order to examine the role that silica substitution plays in enhancing LDH stability, we also determined the enthalpy of formation for a $\mathrm{Ni}$
LDH phase containing a mixed $\mathrm{H}_{3} \mathrm{SiO}_{4}^{-} / \mathrm{CO}_{3}^{2-}$ anion interlayer. The results will be used to develop more accurate models for predicting $\mathrm{Ni}$ speciation in contaminated soils and to assess the range of conditions that lead to the formation of trace metal LDH precipitates.

\section{METHODS}

Most synthesis methods for $\mathrm{LDH}$ precipitates require high temperatures $\left(>100^{\circ} \mathrm{C}\right)$ or $\mathrm{pHs}(8-11)$ unlikely to be found in soils (Reichle, 1986). For this experiment, a series of $\mathrm{Ni}-\mathrm{Al} \mathrm{LDH}$ phases with nitrate and sulfate interlayers was prepared using a low-temperature controlled hydrolysis method based on Taylor (1984) at neutral $\mathrm{pH}$. The $\mathrm{Ni}$ and $\mathrm{Al}$ solutions were prepared by separately dissolving the respective nitrate or sulfate salts in deionized water and then mixing them together

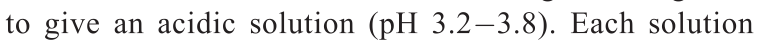
was then titrated with $1 \mathrm{M} \mathrm{NaOH}$ to $\mathrm{pH} 6.9$ and held at this $\mathrm{pH}$ for up to $6 \mathrm{~h}$, until base addition rates dropped below $2 \mathrm{~mL} / \mathrm{h}$. The resulting slurry was then centrifuged at $16,000 \mathrm{~g}$ for $20 \mathrm{~min}$ and the supernatant liquid discarded. The precipitates were washed three times with deionized water to remove entrained solution and absorbed ions, then freeze dried for $48 \mathrm{~h}$. Synthesis was carried out under a $\mathrm{N}_{2}$ atmosphere using solutions sparged with $\mathrm{N}_{2}$ to remove dissolved $\mathrm{CO}_{2}$. For each anion, precipitates were prepared using initial $\mathrm{Ni}$ to $\mathrm{Al}$ solution ratios of 10:1 and 2:1. Additional samples were prepared from a $2: 1 \mathrm{Ni}$ Al solution in the same manner, and then aged for 2 weeks at $65^{\circ} \mathrm{C}$ with constant shaking before centrifugation and washing.

To study the effects of silica substitution into the interlayer, a carbonate $\mathrm{LDH}$ phase was prepared from $\mathrm{Ni}$ and $\mathrm{Al}$ nitrate salts at a 2:1 ratio under atmospheric conditions with a base solution composed of $0.3 \mathrm{M}$ $\mathrm{Na}_{2} \mathrm{CO}_{3}$ and $0.6 \mathrm{M} \mathrm{NaOH}$. After freeze drying, $2 \mathrm{~g}$ of the carbonate-LDH solid were reacted with a $10 \mathrm{~g} / \mathrm{L}$ solution of sodium metasilicate $\left(\mathrm{Na}_{2} \mathrm{SiO}_{3} * 5 \mathrm{H}_{2} \mathrm{O}\right)$ under $\mathrm{N}_{2}$ at $\mathrm{pH} 12.2$, following methods described by Ford et al. (1999) and Depège et al. (1996). The sample was heated to $85^{\circ} \mathrm{C}$ for $48 \mathrm{~h}$ after addition of the $\mathrm{LDH}$ precipitate, and then held at $65^{\circ} \mathrm{C}$ for 2 weeks with constant mixing. A reference $\mathrm{Ni}$ phyllosilicate phase was also prepared using a low-temperature synthesis from co-precipitated base components (Decarreau, 1980; Decarreau et al., 1987; Manceau et al., 1985). The initial gel formed by the reaction of $\mathrm{Na}$ silicate with $\mathrm{Ni}$ sulfate was aged for 14 days at $75^{\circ} \mathrm{C}$ then separated, washed and freeze dried as described above.

$\mathrm{Ni}$ :Al ratios in the solids were determined by flame atomic absorption after hot plate digestion of the precipitate phases in concentrated nitric acid. Anion interlayer identity was determined by Fourier transform infrared (FTIR) using the DRIFT technique, while the molar concentrations of carbonate, sulfate and nitrate in the precipitates were determined by total CNS analysis. 
The water content of the samples was determined by mass loss on heating using high-resolution thermogravimetric analysis (TGA) performed on a TA Instruments 2950. For each sample, $15-20 \mathrm{mg}$ were heated from $30-800^{\circ} \mathrm{C}$ under a $\mathrm{N}_{2}$ atmosphere with a maximum heating rate of $20^{\circ} \mathrm{C} / \mathrm{min}$, a resolution of 5.0 and a sensitivity of 1.0 , with water loss occurring by $190^{\circ} \mathrm{C}$. Weight loss below $75^{\circ} \mathrm{C}$ was attributed to physisorbed compounds, primarily water (Kloprogge et al., 2001).

Precipitate phases were characterized using $\mathrm{CuK} \alpha$ $\mathrm{X}$-ray diffraction (XRD) and X-ray absorption spectroscopy (XAS). NiK $\alpha$ edge spectra were collected in transmission mode at beamline X-11A of the National Synchrotron Light Source at Brookhaven National Laboratory using a $\mathrm{Si}(111)$ monochromator detuned by $25 \%$ to reduce higher-order harmonic interference. Data analysis of the resulting spectra, including background subtraction and $\chi$ function extraction, was performed using WinXAS 3.0 (Ressler, 1998). Ab initio amplitude and phase functions were generated using FEFF7 (Zabinsky et al., 1995). The FEFF input file was created using the hydrotalcite structure (Bellotto et al., 1996) with $\mathrm{Ni}$ replacing the $\mathrm{Mg}$ atoms and a 2:1 Ni:Al ratio. Multi-shell $R$ space fits were performed over a $k$ range of $3-12.75 \AA^{-1}$ and an $R$ range of $1.0-3.18 \AA$, with the $\mathrm{Ni}-\mathrm{Ni}$ and $\mathrm{Ni}-\mathrm{Al}$ bond distances, Debye-Waller factors, and $E_{0}$ shifts constrained to be equal (d'Espinose de la Caillerie et al., 1995). Errors in the fitting were estimated at $\pm 0.020 \AA$ for $R_{\mathrm{Ni}-\mathrm{O}}$ and $R_{\mathrm{Ni}-\mathrm{Ni}}, \pm 60 \%$ for $N_{(\mathrm{Ni}-\mathrm{Al})}$, and $\pm 20 \%$ for $N_{(\mathrm{Ni}-\mathrm{O})}, N_{(\mathrm{Ni}-\mathrm{Ni})}$ and $\Delta E_{0}$, based on the work of Scheidegger et al. (1998).

For carbonate and silicate interlayer LDH phases, enthalpies were measured in a custom-built Tian-Calvet type solution calorimeter (Navrotsky, 1997). Pelletized samples of 5 or $15 \mathrm{mg}$ were dropped from room temperature into platinum crucibles containing $2 \mathrm{PbO}^{*} \mathrm{~B}_{2} \mathrm{O}_{3}$ at $973 \mathrm{~K}$. A flowing argon atmosphere $(60-90 \mathrm{~mL} / \mathrm{min})$ was maintained within the calorimeter to drive off $\mathrm{H}_{2} \mathrm{O}$ and $\mathrm{CO}_{2}$ evolved during the dissolution of water- and carbonate-bearing phases (Navrotsky et al., 1994). The calorimeter was calibrated by measuring the heat content of 5 and $15 \mathrm{mg}$ pellets of corundum.

Although many advances have been made in the optimization of the calorimetry of carbonates and silicates, high-temperature oxide-melt calorimetry techniques have only recently been applied to phases containing sulfate and nitrate (Allada et al., 2005). For this reason, acid-solution calorimetry was used to determine the enthalpies of formation for the $\mathrm{NO}_{3}^{-}$and $\mathrm{SO}_{4}^{2-}$-bearing phases. The enthalpy of solution in $5.0 \mathrm{~N} \mathrm{HCl}$ (Alfa Aesar, standardized) at $298 \mathrm{~K}$ was measured in a commercial Hart Scientific IMC-4400 isothermal calorimeter. Pelletized samples were dissolved in $25 \mathrm{~g}$ of acid under vigorous stirring to ensure complete dissolution. The calorimeter was calibrated by dissolving $5 \mathrm{mg}$ pellets of $\mathrm{KCl}$ (NIST standard reference material 1655) in $25 \mathrm{~g}$ of deionized water under the same stirring conditions.

\section{RESULTS}

\section{Sample characterization}

Formulae for each of the $\mathrm{LDH}$ precipitates prepared in this experiment are listed in Table 1. Nickel to Al ratios in the solid phases ranged from 1.8 to 3.3 , with the less Al-substituted phases resulting from the solutions initially containing 10:1 Ni:Al ratios. The FTIR spectra of all six nitrate and sulfate phases showed peaks corresponding to carbonate ions, and CNS analysis confirmed up to $30 \%$ substitution on a charge equivalent basis of carbonate for nitrate and a $10 \%$ substitution of carbonate for sulfate. This preference for carbonate over nitrate and, to a lesser extent, sulfate, is consistent with previous anion exchange studies on hydrotalcite phases (Miyata, 1983). Given the attempts to exclude carbonate from these systems during synthesis, however, these results suggest that carbonate substitution will occur even at very low aqueous $\mathrm{CO}_{3}^{2-}$ concentrations, and that

Table 1. Formulae and synthesis conditions of Ni-Al layered double hydroxide phases.

\begin{tabular}{|c|c|c|c|c|}
\hline Sample & Formula & $\mathrm{Ni}: \mathrm{Al}^{\dagger}$ & $\begin{array}{l}\text { Temperature } \\
\left({ }^{\circ} \mathrm{C}\right)\end{array}$ & Atmosphere \\
\hline $\mathrm{NO}_{3}(2: 1)$ & $\mathrm{Ni}_{0.65} \mathrm{Al}_{0.35}(\mathrm{OH})_{2}\left[\left(\mathrm{NO}_{3}\right)_{0.21}\left(\mathrm{CO}_{3}\right)_{0.07}\right]^{*} 0.42 \mathrm{H}_{2} \mathrm{O}$ & 2 & 25 & $\mathrm{~N}_{2}$ \\
\hline $\mathrm{NO}_{3}(2: 1, \mathrm{~h})$ & $\mathrm{Ni}_{0.66} \mathrm{Al}_{0.34}(\mathrm{OH})_{2}\left[\left(\mathrm{NO}_{3}\right)_{0.24}\left(\mathrm{CO}_{3}\right)_{0.05}\right]^{*} 0.30 \mathrm{H}_{2} \mathrm{O}$ & 2 & 65 & $\mathrm{~N}_{2}$ \\
\hline $\mathrm{NO}_{3}(10: 1)$ & $\mathrm{Ni}_{0.77} \mathrm{Al}_{0.23}(\mathrm{OH})_{2}\left[\left(\mathrm{NO}_{3}\right)_{0.13}\left(\mathrm{CO}_{3}\right)_{0.05}\right]^{*} 0.60 \mathrm{H}_{2} \mathrm{O}$ & 10 & 25 & $\mathrm{~N}_{2}$ \\
\hline $\mathrm{SO}_{4}(2: 1)$ & $\mathrm{Ni}_{0.66} \mathrm{Al}_{0.34}(\mathrm{OH})_{2}\left[\left(\mathrm{SO}_{4}\right)_{0.15}\left(\mathrm{CO}_{3}\right)_{0.02}\right]^{*} 0.21 \mathrm{H}_{2} \mathrm{O}$ & 2 & 25 & $\mathrm{~N}_{2}$ \\
\hline $\mathrm{SO}_{4}(2: 1, \mathrm{~h})$ & $\mathrm{Ni}_{0.65} \mathrm{Al}_{0.35}(\mathrm{OH})_{2}\left[\left(\mathrm{SO}_{4}\right)_{0.15}\left(\mathrm{CO}_{3}\right)_{0.02}\right]^{*} 0.22 \mathrm{H}_{2} \mathrm{O}$ & 2 & 65 & $\mathrm{~N}_{2}$ \\
\hline $\mathrm{SO}_{4}(10: 1)$ & $\mathrm{Ni}_{0.72} \mathrm{Al}_{0.28}(\mathrm{OH})_{2}\left[\left(\mathrm{SO}_{4}\right)_{0.12}\left(\mathrm{CO}_{3}\right)_{0.02}\right]^{*} 0.43 \mathrm{H}_{2} \mathrm{O}$ & 10 & 25 & $\mathrm{~N}_{2}$ \\
\hline $\mathrm{CO}_{3}(2: 1)^{\#}$ & $\mathrm{Ni}_{0.64} \mathrm{Al}_{0.36}(\mathrm{OH})_{2}\left[\left(\mathrm{CO}_{3}\right)_{0.18}\right] * 0.46 \mathrm{H}_{2} \mathrm{O}$ & 2 & 25 & Air \\
\hline $\mathrm{CO}_{3}(2: 1, \mathrm{~h})^{\#}$ & $\mathrm{Ni}_{0.66} \mathrm{Al}_{0.34}(\mathrm{OH})_{2}\left[\left(\mathrm{CO}_{3}\right)_{0.17}\right]^{*} 0.42 \mathrm{H}_{2} \mathrm{O}$ & 2 & 65 & Air \\
\hline $\mathrm{CO}_{3}(5: 1)^{\#}$ & $\mathrm{Ni}_{0.67} \mathrm{Al}_{0.33}(\mathrm{OH})_{2}\left[\left(\mathrm{CO}_{3}\right)_{0.17}\right] * 0.41 \mathrm{H}_{2} \mathrm{O}$ & 5 & 25 & Air \\
\hline $\mathrm{CO}_{3}(2: 1, \mathrm{~h}, \mathrm{Si})^{\# \#}$ & $\mathrm{Ni}_{0.65} \mathrm{Al}_{0.35}(\mathrm{OH})_{2}\left[\left(\mathrm{CO}_{3}\right)_{0.10}\left(\mathrm{H}_{3} \mathrm{SiO}_{4}\right)_{0.15}\right]^{*} 0.08 \mathrm{H}_{2} \mathrm{O}$ & 2 & 65 & $\mathrm{~N}_{2}$ \\
\hline
\end{tabular}

\footnotetext{
${ }^{\#} \mathrm{CO}_{3}$ interlayer phases described in Allada et al. (2006)

\#\# $\mathrm{CO}_{3}$ interlayer phase after reaction with sodium metasilicate solution

${ }^{\dagger}$ Ratio of $\mathrm{Ni}$ to $\mathrm{Al}$ in initial solution
} 

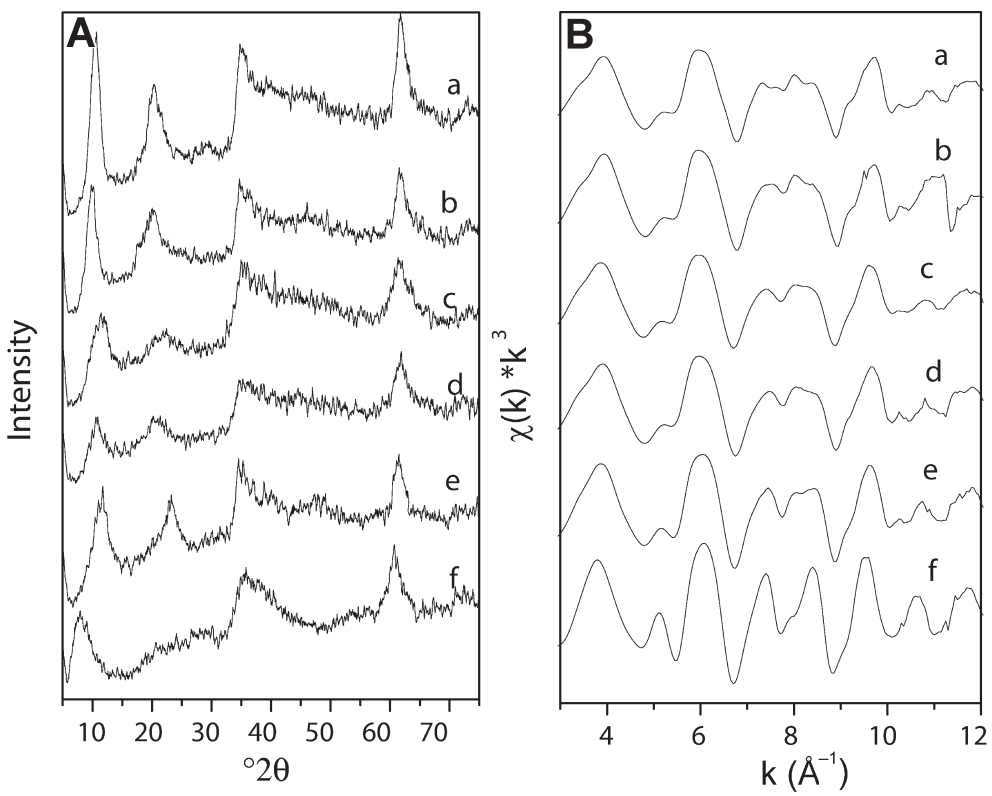

Figure 1. XRD (A) and $\chi$-transformed XAS (B) spectra for synthesized Ni phases: (a) $\mathrm{NO}_{3}(2: 1, \mathrm{~h})$; (b) $\mathrm{SO}_{4}(2: 1, \mathrm{~h})$; (c) $\mathrm{NO}_{3}(2: 1)$; (d) $\mathrm{SO}_{4}(2: 1)$; (e) $\mathrm{CO}_{3}(2: 1, \mathrm{~h}, \mathrm{Si})$; and (f) $\mathrm{Ni}_{3} \mathrm{Si}_{4} \mathrm{O}_{10}(\mathrm{OH})_{2}$.

in most natural systems where carbonate is present, it will probably dominate the interlayers of freshly formed $\mathrm{Ni}$ LDH precipitates. Prior to the silica exchange, the carbonate interlayer phase $\mathrm{CO}_{3}(2: 1)$ had a structure identical to a precipitate phase prepared for our previous study of carbonate-interlayer LDH phases (Allada et al., 2006). After reacting this phase for 2 weeks with the aqueous silica solution, $\sim 40 \%$ of the carbonate ions were replaced with $\mathrm{H}_{3} \mathrm{SiO}_{4}^{-}$. Aside from the anion exchange, the resulting phase $\left(\mathrm{CO}_{3}(2: 1, \mathrm{~h}, \mathrm{Si})\right)$ showed no significant changes in the structure of the octahedral Ni-Al sheets, or the $\mathrm{Ni} / \mathrm{Al}$ ratio. The water content of the interlayer, however, decreased dramatically with silicate substitution. The XRD and XAS data for this phase (Figure 1) are also still consistent with a LDH structure.

The formation of Ni-Al LDH phases was confirmed by XRD and XAS analysis. As seen in the XRD results in Figure 1A, the modified Taylor synthesis method resulted in poorly crystalline $\mathrm{LDH}$ phases for the samples formed at room temperature. Heating at $65^{\circ} \mathrm{C}$ increased the intensity of the peaks at $\sim 10$ and $23^{\circ} 2 \theta$ by $\sim 75 \%$ and $50 \%$, respectively, for both the nitrate and sulfate interlayer phases. As these peaks have been attributed to basal plane reflections (Bellotto et al., 1996), their increasing intensity indicates an increase in sample crystallinity as a result of heating for both phases. The intensities of the peaks for the silicaexchanged carbonate LDH phase indicate that the crystallinity of this phase is intermediate between that of the low-temperature and the heat-treated nitrate and sulfate phases.

Extended X-ray absorption fine structure (EXAFS) spectra of all phases showed the characteristic dampening at $7.5-8 \AA^{-1}$ indicative of $\mathrm{Al}$ substitution into the

Table 2. Structural parameters of synthesized LDH phases.

\begin{tabular}{|c|c|c|c|c|c|c|c|c|c|}
\hline Sample & $N$ & $\frac{\underset{R}{R}}{(\AA)}$ & $\begin{array}{l}\Delta \sigma^{2}\left(\AA^{2}\right) \\
\quad * 10^{-3}\end{array}$ & $\begin{array}{l}\Delta E_{0} \\
(\mathrm{eV})\end{array}$ & $N$ & $\frac{R}{R}(\AA)$ & $\begin{array}{l}-\mathrm{Ni} \\
\quad \sigma^{2}\left(\AA^{2}\right)\end{array}$ & $\begin{array}{l}\Delta E_{0} \\
(\mathrm{eV})\end{array}$ & $\begin{array}{c}\mathrm{Ni}-\mathrm{Al}^{\ddagger} \\
N\end{array}$ \\
\hline $\mathrm{NO}_{3}(2: 1)$ & 5.8 & 2.046 & 6.2 & -5.3 & 4.4 & 3.068 & 8.9 & -2.2 & 1.7 \\
\hline $\mathrm{NO}_{3}(2: 1, \mathrm{~h})$ & 5.3 & 2.052 & 5.7 & -3.1 & 3.3 & 3.066 & 7.9 & -1.0 & 0.8 \\
\hline $\mathrm{NO}_{3}(10: 1)$ & 5.9 & 2.054 & 6.4 & -3.9 & 4.1 & 3.076 & 7.2 & -2.1 & 0.2 \\
\hline $\mathrm{SO}_{4}(2: 1)$ & 6.1 & 2.045 & 6.0 & -4.5 & 3.8 & 3.069 & 8.0 & -0.3 & 1.8 \\
\hline $\mathrm{SO}_{4}(2: 1, \mathrm{~h})$ & 6.4 & 2.061 & 9.1 & -2.2 & 2.9 & 3.026 & 6.7 & -6.0 & 1.2 \\
\hline $\mathrm{SO}_{4}(10: 1)$ & 6.2 & 2.049 & 6.4 & -4.6 & 4.1 & 3.073 & 7.8 & -2.8 & 0.6 \\
\hline $\mathrm{CO}_{3}(2: 1)$ & 6.6 & 2.048 & 6.5 & -5.2 & 4.8 & 3.066 & 8.2 & -2.6 & 1.1 \\
\hline $\mathrm{CO}_{3}(2: 1, \mathrm{~h})$ & 4.8 & 2.057 & 5.8 & -2.0 & 3.1 & 3.053 & 7.6 & -1.1 & 0.8 \\
\hline $\operatorname{CO} 3(5: 1)$ & 6.4 & 2.046 & 6.4 & -3.1 & 4.0 & 3.082 & 7.8 & 0.5 & 0.0 \\
\hline $\mathrm{CO}_{3}(2: 1, \mathrm{~h}, \mathrm{Si})$ & 5.5 & 2.047 & 3.2 & -3.8 & 4.0 & 3.082 & 4.4 & 0.8 & 0.2 \\
\hline
\end{tabular}

\footnotetext{
${ }^{\#} \mathrm{Ni}-\mathrm{Ni}$ and $\mathrm{Ni}-\mathrm{Al}$ distances, Debye-Waller factors and $\Delta E_{0}$ were constrained to remain equal during fitting.
} 
octahedral sheet (Scheinost and Sparks, 2000) (Figure 1B). The structural parameters derived from EXAFS analysis are summarized in Table 2. The $\mathrm{Ni}-\mathrm{Ni}$ bond distances are consistent with those published previously for $\mathrm{Ni} \mathrm{LDH}$ phases (Scheidegger et al., 1998; Scheinost and Sparks, 2000). Coordination numbers for the freshly precipitated samples are also in line with expected values, although destructive interference between $\mathrm{Ni}$ and $\mathrm{Al}$ backscattering results in second shell numbers less than the expected $6 \mathrm{Ni}$ or $\mathrm{Al}$ ions. The samples heated at $65^{\circ} \mathrm{C}$ all show a decrease in second shell coordination to $\sim 4$, suggesting that the heating process may have induced some rearrangement in the LDH structure. The XRD and XAS data for the Ni phyllosilicate precipitate were consistent with previously published data for these phases, and acid digestion results gave a chemical formula of $\mathrm{Ni}_{3} \mathrm{Si}_{4} \mathrm{O}_{10}(\mathrm{OH})_{2}$.

\section{Thermodynamic properties}

Enthalpies of formation for the seven LDH phases synthesized for this work are listed in Table 3, along with previously determined enthalpies for three carbonate interlayer phases, including one phase aged at $65^{\circ} \mathrm{C}$ for 2 weeks $\left(\mathrm{CO}_{3}(2: 1, \mathrm{~h})\right)$, and the enthalpies of several reference Ni phases. The enthalpies of formation $\left(\Delta H_{\mathrm{f}}{ }^{0}\right)$ of all Ni-LDH phases are substantially more negative than those of either $\mathrm{Ni}(\mathrm{OH})_{2}$ or $\mathrm{NiCO}_{3}$, with some variation between the different anion interlayer phases. In particular, the samples with nitrate interlayers have less negative enthalpies of formation than the equivalent sulfate or carbonate interlayer phases despite still containing up to $25 \%$ carbonate ions in the interlayer. This trend is consistent with the preference for carbonate over nitrate in the anion interlayer seen in anionexchange studies.
The fourth column of Table $3, \Delta H_{\mathrm{f}}^{\mathrm{scc}}$, gives the difference between the experimentally determined enthalpy of formation from the elements for each sample and the calculated enthalpy of formation from the single cation end-members $\left(\Delta H_{\mathrm{f}}^{\text {end }}\right)$. For example, for sample $\mathrm{CO}_{3}(2: 1), \Delta H_{\mathrm{f}}^{\text {end }}$ is calculated using the expression:

$$
\begin{aligned}
& \mathrm{Ni}_{0.64} \mathrm{Al}_{0.36}(\mathrm{OH})_{2}\left[\left(\mathrm{CO}_{3}\right)_{0.18}\right]^{*} 0.49 \mathrm{H}_{2} \mathrm{O}= \\
& 0.46 \mathrm{Ni}(\mathrm{OH})_{2}+0.18 \mathrm{NiCO}_{3}+0.36 \mathrm{Al}(\mathrm{OH})_{3}+0.49 \mathrm{H}_{2} \mathrm{O}
\end{aligned}
$$

$\Delta H_{\mathrm{f}}^{\mathrm{scc}}$ is then determined as:

$$
\Delta H_{\mathrm{f}}^{\mathrm{scc}}=\Delta H_{\mathrm{f}}^{0} \text { (measured) }-\Delta H_{\mathrm{f}}^{\text {end }}
$$

In order to determine free energies of formation for each phase, the corresponding $\Delta G_{\mathrm{f}}^{\text {end }}$ was calculated from the free energies of the end-member products. The free energy of formation of the sample from the elements is then given by

$$
\Delta G_{\mathrm{f}}^{0}=\Delta G_{\mathrm{f}}^{\text {end }}+\Delta G_{\mathrm{f}}^{\mathrm{scc}}
$$

where

$$
\Delta G_{\mathrm{f}}^{\mathrm{scc}}=\Delta H_{\mathrm{f}}^{\mathrm{scc}}-T \Delta S^{\mathrm{scc}}
$$

We used an approximate value for $T \Delta S^{\mathrm{scc}}$ of $-1.9 \mathrm{~kJ} / \mathrm{mol}$ at $298 \mathrm{~K}$, a value based on entropy measurements of a structurally similar $\mathrm{Mg}$ hydrotalcite phase (Allada et al., 2005). Given the small contribution of this term relative to the enthalpies of these precipitates, small variations between this model phase and the Ni LDHs synthesized here are unlikely to have a significant effect on the resulting free energies. Table 4 gives the resulting free energies of formation for each sample phase, based on values for the end-member phases listed in supplementary Table S1.

The effects of heat ageing on LDH enthalpy were mixed. Enthalpies of formation from the elements for the

Table 3. Thermodynamic properties of Ni LDH phases and reference Ni precipitates.

\begin{tabular}{lccccl}
\hline Sample & $\begin{array}{c}\Delta H_{\text {sol }} \\
(\mathrm{kJ} / \mathrm{mol})\end{array}$ & $\begin{array}{c}\Delta H_{\mathrm{f}}^{0} \\
(\mathrm{~kJ} / \mathrm{mol})\end{array}$ & $\begin{array}{c}\Delta H_{\mathrm{f}}^{\text {scc }} \\
(\mathrm{kJ} / \mathrm{mol})\end{array}$ & $\begin{array}{c}\text { Hydrated } \\
\Delta H_{\mathrm{f}}^{\text {scc }}\end{array}$ & Reference \\
\hline $\mathrm{NO}_{3}(2: 1)$ & $-73.20 \pm 1.25$ & $-942.41 \pm 2.07$ & -20.00 & -12.74 & This work \\
$\mathrm{NO}_{3}(2: 1, \mathrm{~h})$ & $-64.96 \pm 1.12$ & $-904.03 \pm 1.94$ & -28.11 & -19.82 & This work \\
$\mathrm{NO}_{3}(10: 1)$ & $-72.71 \pm 1.20$ & $-908.42 \pm 2.02$ & -23.36 & -18.87 & This work \\
$\mathrm{SO}_{4}(2: 1)$ & $-65.22 \pm 0.61$ & $-940.30 \pm 1.64$ & -31.12 & -16.92 & This work \\
$\mathrm{SO}_{4}(2: 1, \mathrm{~h})$ & $-59.34 \pm 0.86$ & $-957.52 \pm 1.89$ & -36.84 & -23.75 & This work \\
$\mathrm{SO}_{4}(10: 1)$ & $-61.34 \pm 0.52$ & $-952.78 \pm 1.71$ & -35.86 & -24.51 & This work \\
$\mathrm{CO}_{3}(2: 1)$ & & $-987.30 \pm 1.53$ & -17.72 & & (Allada et al., 2006) \\
$\mathrm{CO}_{3}(2: 1, \mathrm{~h})$ & & $-950.57 \pm 0.93$ & -8.97 & & (Allada et al., 2006) \\
$\mathrm{CO}_{3}(5: 1)$ & & $-930.47 \pm 2.06$ & -19.46 & & (Allada et al., 2006) \\
$\mathrm{CO}_{3}(2: 1, \mathrm{~h}, \mathrm{Si})$ & $216.97 \pm 1.19$ & $-1132.27 \pm 1.37$ & -29.31 & & This work \\
$\mathrm{Ni}_{3} \mathrm{Si}_{4} \mathrm{O}_{10}(\mathrm{OH})_{2}$ & $769.81 \pm 17.66$ & $-4954.32 \pm 18.45$ & & & This work \\
$\beta-\mathrm{Ni}_{2}(\mathrm{OH})_{2}$ & & $-540.34 \pm 1.37$ & & & (Allada et al., 2006) \\
$\mathrm{NiCO}_{3}$ & & -689.1 & & & (Naumov et al., 1974)
\end{tabular}

$\Delta H_{\mathrm{sol}}(\mathrm{kJ} / \mathrm{mol})=$ enthalpy of solution in $5.0 \mathrm{~N} \mathrm{HCl}$

$\Delta H_{\mathrm{f}}^{0}(\mathrm{~kJ} / \mathrm{mol})=$ enthalpy of formation from the elements at $298.15 \mathrm{~K}$ and $1 \mathrm{bar}$

$\Delta H_{\mathrm{f}}^{\mathrm{scc}}(\mathrm{kJ} / \mathrm{mol})=$ difference between measured enthalpy of formation and enthalpy of formation from single cation components

Hydrated $\Delta H_{\mathrm{f}}^{\mathrm{scc}}=\Delta H_{\mathrm{f}}^{\mathrm{scc}}$ calculated using $\mathrm{Ni}\left(\mathrm{NO}_{3}\right)_{2} * 6 \mathrm{H}_{2} \mathrm{O}$ or $\mathrm{NiSO}_{4} * 6 \mathrm{H}_{2} \mathrm{O}$ instead of anhydrous salts 
Table 4. Free energies of formation of Ni LDH phases and reference Ni precipitates at $298.15 \mathrm{~K}$ and 1 bar.

\begin{tabular}{lccc}
\hline Sample & $\begin{array}{c}\Delta G_{\mathrm{f}}^{\text {end }} \\
(\mathrm{kJ} / \mathrm{mol})\end{array}$ & $\begin{array}{c}\Delta G_{\mathrm{f}}^{\mathrm{scc}} \\
(\mathrm{kJ} / \mathrm{mol})\end{array}$ & \multicolumn{1}{c}{$\Delta G_{\mathrm{f}}^{0}$} \\
$(\mathrm{~kJ} / \mathrm{mol})$
\end{tabular}

\# Estimated $\Delta G_{\mathrm{f}}{ }^{0}$ value assuming $S^{0}$ equivalent to talc

† Values from Naumov et al. (1974).

* Estimated from solid-solution model

heat-aged carbonate and nitrate interlayer samples $\left(\mathrm{CO}_{3}(2: 1, \mathrm{~h})\right.$ and $\left.\mathrm{NO}_{3}(2: 1, \mathrm{~h})\right)$ were less negative than the untreated samples despite the increased crystallinity seen in the XRD patterns, while the enthalpy of formation for $\mathrm{SO}_{4}(2: 1, \mathrm{~h})$ was only $15 \mathrm{~kJ} / \mathrm{mol}$ more negative than the original phase. The differences in waters of hydration between the heat-aged and original phases appears to be a more significant factor than any increase in the ordering of the octahedral sheets, as the increase or decrease in enthalpy correlates with the increase or decrease in waters of hydration between the original and heat-treated phases. These results suggest that interlayer water molecules are likely to play a significant role in determining the thermodynamic properties of the LDH phases.

\section{Solid-solution modeling}

The mixed Ni-Al hydroxide phases examined here can be represented as binary solid-solutions using as the two end-members $\mathrm{Ni}(\mathrm{OH})_{2}$ and a hypothetical compound $\mathrm{Al}(\mathrm{OH})_{2}{ }^{+}\left(\mathrm{A}^{n-}\right)_{1 / n}$, where the hypothetical Al hydroxide compound has a layered structure of positively charged $\mathrm{Al}(\mathrm{OH})_{2}^{+}$sheets interspersed with interlayered $\mathrm{A}^{n-}$ anions. The enthalpy of formation for each Ni-LDH phase could then be written using the following expression

$\Delta G_{\mathrm{F}, \mathrm{LDH}}^{0}=$

$$
(1-x)^{*} \Delta G_{\mathrm{f}, \mathrm{Ni}(\mathrm{OH})_{2}}^{0}+x^{*} \Delta G_{\mathrm{f}, \mathrm{Al}(\mathrm{OH})_{2}(\mathrm{~A})}^{0}+\Delta G_{\mathrm{mix}}^{0}
$$

where $x$ is the extent of Al substitution. While such a mixture would not be ideal due to the differences between $\mathrm{Al}^{3+}$ and $\mathrm{Ni}^{2+}$, it is reasonable to assume a regular solid-solution in which case we can describe the free enthalpy of mixing by the equation

$$
\Delta G_{\text {mix }}^{0}=\Delta G_{\text {mix,ideal }}^{0}+\mathrm{A}_{0} * x^{*}(1-x)
$$

with $A_{0}$ as a constant, independent of pressure, temperature, or composition. For each type of anion interlayer $\left(\mathrm{CO}_{3}^{2-}, \mathrm{SO}_{4}^{2-}, \mathrm{NO}_{3}^{-}\right)$, therefore, it is necessary to determine both $\mathrm{A}_{0}$ and the free energy of the hypothetical Al layered hydroxide phase. The free energy of formation for $\mathrm{Ni}(\mathrm{OH})_{2}$, was taken to be $-459.1 \mathrm{~kJ} / \mathrm{mol}$, the value for $\beta-\mathrm{Ni}(\mathrm{OH})_{2}$ determined by Allada et al. (2006). While $\alpha-\mathrm{Ni}(\mathrm{OH})_{2}$ would be a closer analog to Ni in the LDH phase, no good values for the free energy of this phase are currently available.

At some value of $x$, the free energy of the solidsolution system is at a minimum. Following Bourrié et al. (2004), it is possible to rewrite $\mathrm{A}_{0}$ at this value as a function only of the free energies of the two endmembers, giving the equation

$$
\mathrm{A}_{0}=\frac{\Delta G_{\mathrm{f}, \mathrm{Ni}(\mathrm{OH})_{2}(\mathrm{~A})}^{0}+\mathrm{R} T \ln \left(\frac{x_{\min }}{1-x_{\min }}\right)}{1-2 x_{\min }}
$$

where $x_{\min }$ is the value of $x$ with minimal free energy. With this substitution, it is possible to solve for the free energy of the hypothetical Al hydroxide-anion phase using the measured values of $\Delta G_{\mathrm{f}}{ }^{0}$ listed in Table 4 . We used the average values of $\mathrm{A}_{0}$ and $\Delta G_{\mathrm{f}}{ }^{0},(n=3)$ to construct solid-solution diagrams for each of the three anion interlayers.

In general, the range of $x$ actually seen for synthesized LDH phases varies from $\sim 0.2$ to $\sim 0.33$ (Cavani et al., 1991), although greater Al substitution $(x=0.44)$ has been achieved under high-pressure conditions (Pausch et al., 1986). Brindley and Kikkawa (1979) suggested that the practical limits on $x$ depend on shielding like metal ions from each other. Above 
Table 5. Parameters for the binary solid-solution models for Ni LDH phases at $298.15 \mathrm{~K}$ and 1 bar.

\begin{tabular}{lcccc}
\hline Anion & $\mathrm{A}_{0}(\mathrm{~kJ} / \mathrm{mol})$ & $\begin{array}{c}\Delta G_{\mathrm{f}}^{0}(\mathrm{~kJ} / \mathrm{mol}) \\
\text { at } x=0.28\end{array}$ & $\begin{array}{c}\Delta G_{\mathrm{f}}^{0}(\mathrm{~kJ} / \mathrm{mol}) \\
\mathrm{Al}(\mathrm{OH})_{2}^{+}\left(\mathrm{A}^{n-}\right)_{1 / n}\end{array}$ & $\begin{array}{c}\Delta H_{\mathrm{f}}^{0}(\mathrm{~kJ} / \mathrm{mol}) \\
\mathrm{Al}(\mathrm{OH})_{2}^{+}\left(\mathrm{A}^{n-}\right)_{1 / n}\end{array}$ \\
\hline $\mathrm{CO}_{3}^{2-}$ & -5204 & -869.3 & 1829 & 1667 \\
$\mathrm{SO}_{4}^{2-}$ & -4891 & -844.7 & 1691 & 1489 \\
$\mathrm{NO}_{3}^{-}$ & -4345 & -800.4 & 1450 & 1199 \\
\hline
\end{tabular}

$x=0.33$, where the ratio of $\mathrm{Ni}$ to $\mathrm{Al}$ falls $<2: 1$, islands of $\mathrm{Al}(\mathrm{OH})_{3}$ may begin to form in the precipitate. Somewhere below $x=0.25$, neighboring $M^{2+}$ atoms form nuclei for the development of the corresponding metal hydroxide (Brindley, 1980). Based on Reichle's (1986) reported results for $\mathrm{Ni} \mathrm{LDH}$ synthesis, we have set the range for pure $\mathrm{Ni} \mathrm{LDH}$ formation at $0.23 \leqslant x \leqslant$ 0.33 , and choose $x_{\min }=0.28$, the center of this range, in our determination of solid-solution parameters for the Ni-LDH systems described here.

Parameters for solving equation 8 are listed in Table 5 for $\mathrm{CO}_{3}^{2-}, \mathrm{SO}_{4}^{2-}$ and $\mathrm{NO}_{3}^{-}$anion interlayer phases, along with the values of $\Delta G_{\mathrm{f}}{ }^{0}$ at $x=x_{\min }$ for each system. In the case of the $\mathrm{NO}_{3}^{-}$and $\mathrm{SO}_{4}^{2-}$ interlayer systems, carbonate contamination in the interlayers of the experimental samples has been ignored, a factor that is probably more significant for the nitrate than the sulfate system. Figure 2 a shows the full solid-solution diagram for the sulfate interlayer system over all possible ranges of $x$. While free energies of formation are positive for $x \geqslant 0.6$, the free energies of formation for mixed $\mathrm{Ni}(\mathrm{OH})_{2}$ and $\mathrm{Al}(\mathrm{OH})_{3}$ are more negative than for the solid solution for $x \geqslant 0.4$. This places an upper limit of formation for $\mathrm{Ni} \mathrm{LDH}$ phases at or below $x=0.4$ (Génin et al., 2001), consistent with most reported experimental results. Comparison of the solid-solution

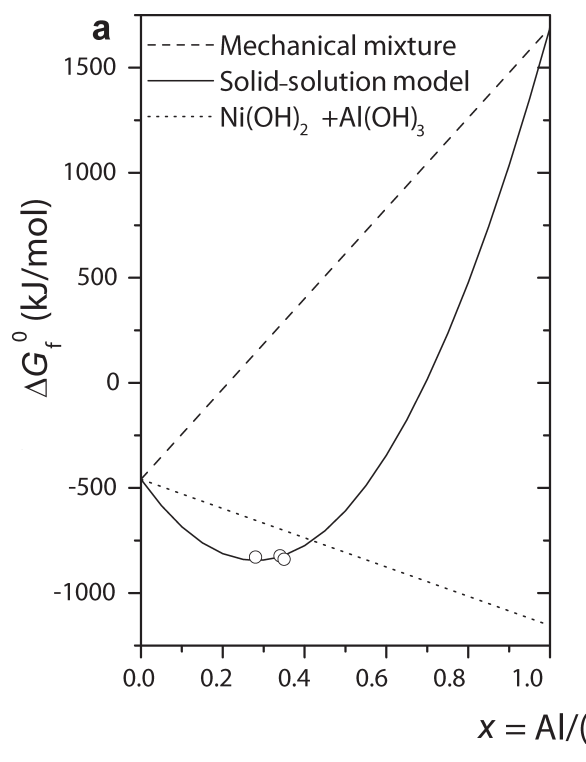

diagrams for the three anion interlayers (Figure 2b) suggests that the stability of the anion interlayers will probably increase in the order $\mathrm{NO}_{3}^{-}<\mathrm{SO}_{4}^{2-}<\mathrm{CO}_{3}^{2-}$

\section{Silica substitution into the anion interlayer}

Reaction of a carbonate-interlayered $\mathrm{LDH}$ phase similar to $\mathrm{CO}_{3}(2: 1)$ with a $\mathrm{Na}$ metasilicate solution resulted in replacement of $\sim 40 \%$ of the interlayered $\mathrm{CO}_{3}^{2-}$ with $\mathrm{H}_{3} \mathrm{SiO}_{4}^{-}$. The resulting phase, $\mathrm{CO}_{3}(2: 1, \mathrm{~h}, \mathrm{Si})$, had the most negative enthalpy of formation of any of the phases examined in this study. From the $\mathrm{CO}_{3}^{2-}$ solid-solution model, we can estimate the free energy of the precursor carbonate phase, $\mathrm{Ni}_{0.65} \mathrm{Al}_{0.35}(\mathrm{OH})_{2}\left[\left(\mathrm{CO}_{3}\right)_{0.175}\right]^{*} 0.43 \mathrm{H}_{2} \mathrm{O}$, as $-840.6 \mathrm{~kJ} / \mathrm{mol}$. (The number of moles of water of hydration is obtained by averaging $m$ for the three experimental $\mathrm{CO}_{3}$ phases.) The free energy of reaction for silica exchange,

$$
\begin{aligned}
& \mathrm{Ni}_{0.65} \mathrm{Al}_{0.35}(\mathrm{OH})_{2}\left[\left(\mathrm{CO}_{3}\right)_{0.175}\right]^{*} 0.43 \mathrm{H}_{2} \mathrm{O}+ \\
& 0.15 \mathrm{H}_{4} \mathrm{SiO}_{4} \rightleftharpoons 0.075 \mathrm{CO}_{3}^{2-}+ \\
& \mathrm{Ni}_{0.65} \mathrm{Al}_{0.35}(\mathrm{OH})_{2}\left[\left(\mathrm{CO}_{3}\right)_{0.1}\left(\mathrm{H}_{3} \mathrm{SiO}_{4}\right)_{0.15}\right]^{*} 0.08 \mathrm{H}_{2} \mathrm{O}+ \\
& 0.38 \mathrm{H}_{2} \mathrm{O}+0.15 \mathrm{H}^{+}
\end{aligned}
$$

is therefore $-11.2 \mathrm{~kJ} / \mathrm{mol}$, or $-74.7 \mathrm{~kJ} / \mathrm{mol} \mathrm{H} \mathrm{H}_{3} \mathrm{SiO}_{4}^{-}$ exchanged (see Table S2 for the free energies of formation for aqueous phases used in this calculation). This result provides a thermodynamic basis for the $\mathrm{Si}$ substitution into surface LDH phases over time seen in

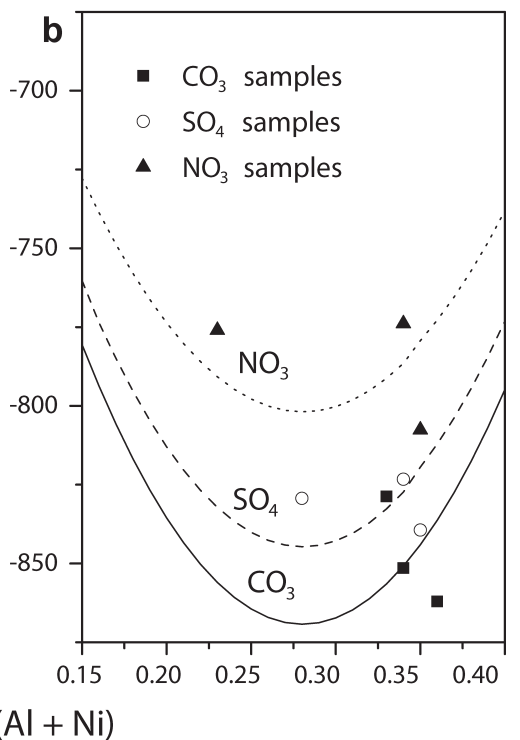

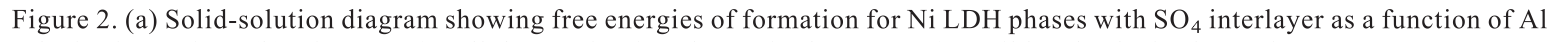
substitution ratio $x$. (b) Diagrams for all three anion interlayers in the range of possible Al substitution ratios. 
previous experiments (Ford et al., 1999, 2001). The substantial decrease in interlayer water content during silica substitution is also consistent with a transformation to a more phyllosilicate-type phase with alternating octahedral and tetrahedral sheets.

The enthalpy of formation for the phyllosilicate phase synthesized in this experiment was by far the most negative of the $\mathrm{Ni}$ precipitates examined. Table 4 also presents an estimated value of the Gibbs free energy value of this phase. As no data were available for the standard entropy $\left(S^{0}\right)$ of this or any sufficiently similar Ni phase, the Gibbs free energy for this phase was calculated assuming a standard entropy $S^{0}=260 \mathrm{~J} \mathrm{~mol}^{-1} \mathrm{~K}^{-1}$, equal to that for talc $\left(\mathrm{Mg}_{3} \mathrm{Si}_{4} \mathrm{O}_{10}(\mathrm{OH})_{2}\right)$, the analogous $\mathrm{Mg}$ phyllosilicate compound (Robie and Hemingway, 1995). This introduces some uncertainty into the actual values of $\Delta G_{\mathrm{f}}{ }^{0}$ for the $\mathrm{Ni}$ phyllosilicate phase, but the entropy contribution is sufficiently small that the free energy of this phase is unquestionably much more negative than that for any of the LDH phases. This result confirms that the transition from Ni LDH phases to phyllosilicates proposed in previous works is a thermodynamically favorable reaction.

\section{DISCUSSION}

\section{Modeling LDH thermodynamic properties}

A number of different models can be used to predict LDH thermodynamic properties based on combinations of simpler, but similar, binary compounds for which thermodynamic properties are already known. These models give generally similar results that agree well with available experimental data for a variety of $\mathrm{LDH}$ phases (Bravo-Suárez et al., 2004a, 2004b). Using the $\Delta H_{\mathrm{f}}^{\mathrm{scc}}$ model described above, Allada et al. (2006) calculated enthalpies of formation for a variety of $\mathrm{Mg}$, $\mathrm{Co}$ and $\mathrm{Ni} \mathrm{LDH}$ phases with carbonate interlayers that were between 4 and $19 \mathrm{~kJ} / \mathrm{mol}$ less negative than experimental values. For the nitrate-, sulfate- and silica-exchanged $\mathrm{Ni}$ LDH phases, however, $\Delta H_{\mathrm{f}}^{\mathrm{scc}}$ values range from -20 to $-35 \mathrm{~kJ} / \mathrm{mol}$, indicating a greater degree of error in the model predictions when carbonate is not the dominant interlayer anion. Unlike $\mathrm{Ni}$ carbonate, Ni nitrate and Ni sulfate phases are thermodynamically much more stable when hydrated, suggesting that interlayer waters may play a stabilizing role in these phases. Recalculation of $\Delta H_{\mathrm{f}}{ }^{\mathrm{scc}} \mathrm{using}$ $\mathrm{NiSO}_{4} * 6 \mathrm{H}_{2} \mathrm{O}$ and $\mathrm{Ni}\left(\mathrm{NO}_{3}\right)_{2} * 6 \mathrm{H}_{2} \mathrm{O}$ for the end-member components instead of the anhydrous salts resulted in values ranging from -11.0 to -19.6 for the nitrate interlayer phases and -16.8 to -23.0 for the sulfate interlayer phases, only slightly more negative than the values for carbonate interlayer phases. Thus, this mechanical mixture model can be used to provide a reasonable first approximation for enthalpies of formation of $\mathrm{Ni} \mathrm{LDH}$ phases where the chemical formula of the phase is known.
The effect of interlayer water molecules on the thermodynamic properties of the $\mathrm{Ni} \mathrm{LDH}$ phases also highlights the largest limitation of the solid-solution model generated above with respect to generalizing these experimental results. The solid-solution model ignores any contribution from interlayer waters when determining free energy (or enthalpy). As the amount of interlayer water can vary considerably from phase to phase, this introduces some uncertainty into attempts to translate the results generated by the model into applications such as the determination of solubility product constants. However, this approach is less dependent upon the availability and quality of thermodynamic data for other phases than the mechanical mixture model.

\section{Geochemical modeling of LDH precipitation}

Geochemical modeling of LDH precipitate formation in simulated soil systems was carried out using Visual MINTEQ v. 2.30 (Gustafsson, 2004). Visual MINTEQ is a MS-Windows version of MINTEQ v. 4.0 (Allison et al., 1991), a chemical equilibrium model for predicting metal speciation and solubility in natural waters. For these calculations, we used Lindsay's revised database (Lindsay and Ajwa, 1995), modified to include synthesized LDH phases. Solubility product constants $\left(\mathrm{K}_{\mathrm{sp}}\right)$ for $\mathrm{Ni} \mathrm{LDH}$ phases with $\mathrm{CO}_{3}^{2-}, \mathrm{SO}_{4}^{2-}$ and $\mathrm{NO}_{3}^{-}$anion interlayers and 33\% Al substitution $(x=0.33)$ were calculated for the reaction

$$
\begin{aligned}
& \mathrm{Ni}_{(1-x)} \mathrm{Al}_{x}(\mathrm{OH})_{2}\left[\mathrm{~A}^{n-}\right]_{(x / n)} * m \mathrm{H}_{2} \mathrm{O}+2 \mathrm{H}^{+} \rightleftharpoons \\
& \quad(1-x) \mathrm{Ni}^{2+}+x \mathrm{Al}^{3+}+(x / n) \mathrm{A}^{n-}+(2+m) \mathrm{H}_{2} \mathrm{O}
\end{aligned}
$$

from the free energy of reaction $\left(\Delta G_{\mathrm{rxn}}\right)$ as follows:

$$
\Delta G_{\mathrm{rxn}}=-\mathrm{R} T \ln \left(\mathrm{K}_{\mathrm{sp}}\right)
$$

where $T=298.15 \mathrm{~K}$ and $\mathrm{R}$ is the ideal gas constant $(8.314 \mathrm{~J} / \mathrm{mol} \mathrm{K}) . \Delta G_{\mathrm{f}}{ }^{0}$ values for each phase were calculated from the solid-solution models in Table 5. Water content $(\mathrm{m})$ for the carbonate and nitrate interlayer phases was set at 0.505 , the maximum possible value for this degree of Al substitution (Miyata, 1975). Water content for the $\mathrm{SO}_{4}^{2-}$ phase was set at 0.26 , as our experimental results, as well as other work (Brindley and Kikkawa, 1980), suggest that the water content of sulfate interlayer phases is $50 \%$ or less of this theoretical maximum. Free energy values for the other reactants and products were taken from Robie and Hemingway (1995) and are listed in supplementary Table S2. A similar approach was used to calculate the solubility-product constant for the synthesized $\mathrm{Ni}$ phyllosilicate phase.

Solubility-product constants for the $\mathrm{CO}_{3}^{2-}, \mathrm{SO}_{4}^{2-}$ and $\mathrm{NO}_{3}^{-}$phases (Table 4) are greater than the solubility product of $10^{1.33}$ for a carbonate interlayer $\mathrm{Ni} \mathrm{LDH}$ phase reported by Johnson and Glasser (2003) based on steady-state dissolution reactions. However, all of these phases are less soluble than $\mathrm{Ni}(\mathrm{OH})_{2}$ by several orders of 
magnitude. The greater solubility of the $\mathrm{NO}_{3}^{-}$phase is consistent with carbonate and sulfate exchange for nitrate in LDH interlayers (Miyata, 1983). The results of that study, however, would also indicate that the carbonate phase should be less soluble than the sulfate phase. This discrepancy is probably due to the assumed values for the interlayer water content. In general, actual $\mathrm{CO}_{3}^{2-}$ interlayer phases have less than the maximum number of interlayer waters (which would decrease solubility from the estimated value), while increasing $m$ from 0.26 to 0.29 in the sulfate phase would result in a $\mathrm{K}_{\mathrm{sp}}=10^{4.4}$. These results also indicate a substantial effect of interlayer anion identity of LDH solubility.

Using these solubility product constants, the saturation indices of the various LDH phases were determined in a model groundwater (Table 6) in contact with several different clay substrates and amorphous silica. Figure 3 shows the resulting saturation indices at a total dissolved $\mathrm{Ni}$ concentration of $50 \mu \mathrm{mol} / \mathrm{L}$ for soils composed primarily of kaolinite, pyrophyllite, montmorillonite and gibbsite. The sulfate and carbonate interlayer LDH phases are less soluble than $\mathrm{Ni}(\mathrm{OH})_{2}$ over the entire $\mathrm{pH}$
Table 6. Composition of model groundwater (from Tang and Johannesson (2003)).

\begin{tabular}{lc}
\hline Solute & $\begin{array}{c}\text { Concentration } \\
(\mathrm{mM})\end{array}$ \\
\hline $\mathrm{HCO}_{3}$ & 0.957 \\
$\mathrm{SO}_{4}$ & 0.117 \\
$\mathrm{NO}_{3}$ & 0.100 \\
$\mathrm{Cl}$ & 0.22 \\
$\mathrm{Na}$ & 0.74 \\
$\mathrm{~K}$ & 0.059 \\
$\mathrm{Ca}$ & 0.375 \\
$\mathrm{Mg}$ & 0.171 \\
$\mathrm{Fe}$ & 0.012
\end{tabular}

range in each system, and could play a significant role in $\mathrm{Ni}$ speciation under these conditions. Even a reduction in the aqueous $\mathrm{Ni}$ concentration to $5 \mu \mathrm{M}$ would still result in carbonate $\mathrm{LDH}$ saturation at more basic $\mathrm{pH}$ in all systems except montmorillonite. These calculations also indicate the significant role that sulfate interlayer LDH phases could play in controlling $\mathrm{Ni}$ speciation in
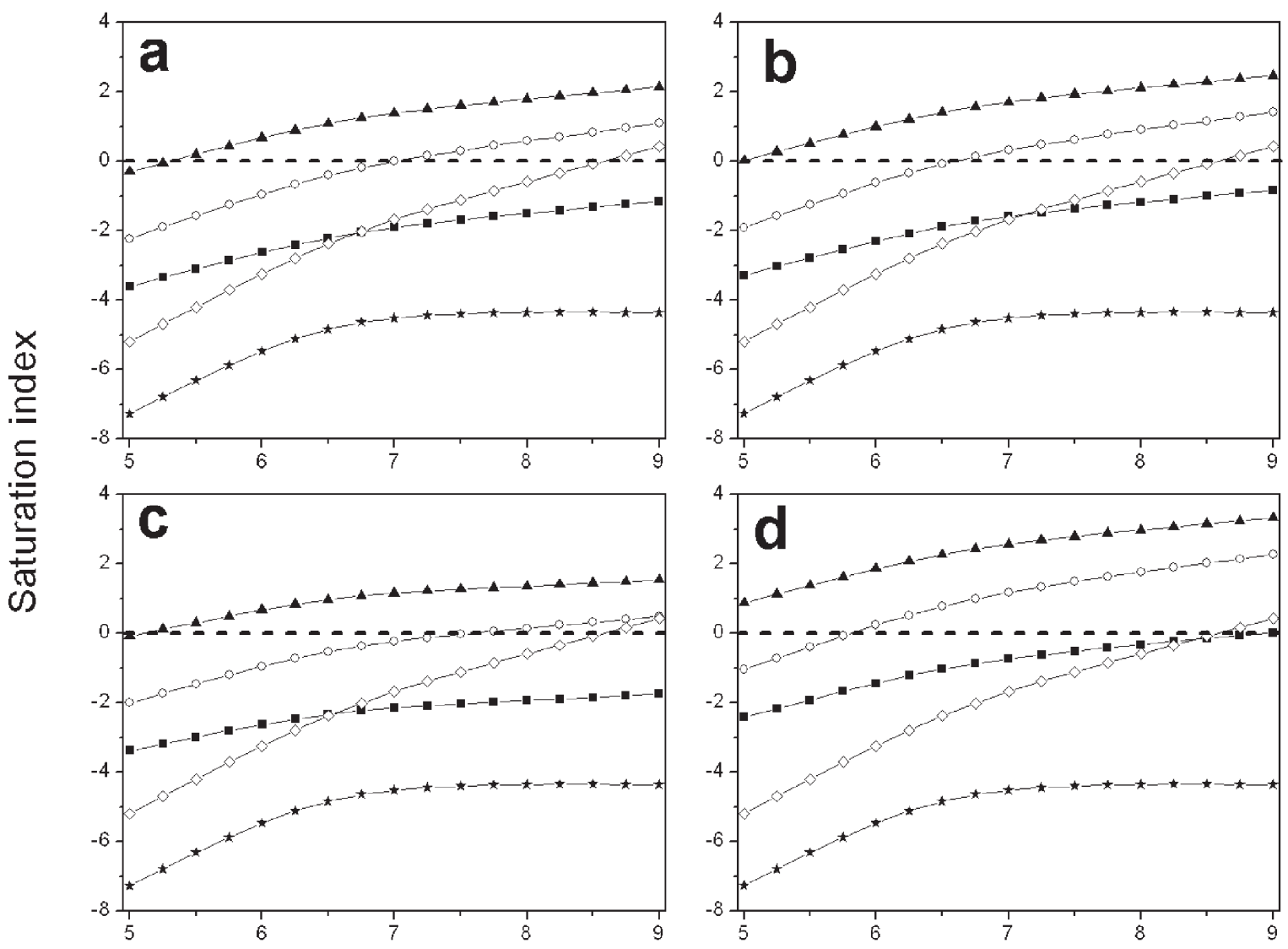

$\mathrm{pH}$

Figure 3. Saturation indices for Ni-precipitate phases in contact with (a) pyrophyllite, (b) kaolinite, (c) montmorillonite, and (d) gibbsite using the model groundwater in Table 6 and $50 \mu \mathrm{M}$ dissolved Ni. $\left(-\mathrm{O}_{-}\right) \mathrm{LDH}_{-} \mathrm{CO}_{3},(-\boldsymbol{\Lambda}-) \mathrm{LDH}_{-} \mathrm{SO}_{4},(-\mathbf{\square}-) \mathrm{LDH}_{-}$ $\mathrm{NO}_{3},(-\diamond-) \mathrm{Ni}(\mathrm{OH})_{2}$, and $\left(-^{*}-\right) \mathrm{NiCO}_{3}$. Dashed line indicates $\mathrm{SI}=0$. 
groundwater systems even when carbonate is not present. The nitrate interlayer $\mathrm{LDH}$, however, is less likely to form compared to $\mathrm{Ni}(\mathrm{OH})_{2}$ above $\mathrm{pH} 6.5-7$ and thus will not form regardless of $\mathrm{Ni}$ concentration unless gibbsite predominates or dissolved nitrate concentrations are extremely high.

Calculations of the saturation index for the synthesized Ni phyllosilicate phase under these conditions give values $\geqslant 82$ for all four systems, suggesting that $\mathrm{Ni}$ silicate phases should be the dominant $\mathrm{Ni}$ precipitate phase. However, this is also true in situations where the formation of $\mathrm{Ni} \mathrm{LDH}$ phases has been observed experimentally. Applications of the solubility product constants generated here to the experimental conditions outlined by Scheckel et al. (2000) and Scheidegger et al. (1998) also predict the formation of $\mathrm{Ni}$ silicate phases on gibbsite and pyrophyllite, not the LDH phases observed in those studies. The kinetics of Ni phyllosilicate precipitation, however, are sufficiently slow that the less thermodynamically favored LDH phases formed on these surfaces instead. Silica substitution into the interlayers of these phases will eventually result in the transformation of these LDHs to the more stable $\mathrm{Ni}$ phyllosilicate phases, but the rate of substitution is not known, and very long times may be required for full transformation to phyllosilicate phases.

\section{CONCLUSIONS}

The enthalpy data presented here show a substantial effect of anion interlayer on the thermodynamic properties and behavior of Ni layered double hydroxide phases. Enthalpy and free energies of formation for $\mathrm{Ni} \mathrm{LDH}$ phases increase in the order $\mathrm{CO}_{3}^{2-}<\mathrm{SO}_{4}^{2-}<\mathrm{NO}_{3}^{-}$, confirming that carbonate is the most stable of the common inorganic anion interlayer species. $\mathrm{Ni} \mathrm{LDH}$ phases are thermodynamically favored over pure $\mathrm{Ni}$ hydroxides on soil minerals containing soluble Al, and become increasingly likely at $\mathrm{pH}$ values $\geqslant 6.5$. The substitution of silica for carbonate in the interlayer is a thermodynamically favored process that represents the first step in the transformation of $\mathrm{Ni}$ LDHs to phyllosilicate phases with substantially lower Ni solubility than hydroxide phases. Based on these results, the formation of $\mathrm{Ni} \mathrm{LDH}$ surface precipitates may significantly reduce $\mathrm{Ni}$ mobility and bioavailability in contaminated soils where minerals such as kaolinite and pyrophyllite are present. In these systems, thermodynamic modeling can provide a reasonably accurate approximation of $\mathrm{Ni}$ speciation, as long as efforts are made to account for factors such as $\mathrm{Ni}$ sorption or complexation with soil organic matter.

\section{ACKNOWLEDGMENTS}

Funding for this project was provided by the US Environmental Protection Agency through the Center for the Study of Metals in the Environment at the University of Delaware and by the Unidel Foundation. Portions of this research were carried out at the National Synchrotron Light Source, Brookhaven National Laboratory, which is supported by the US Department of Energy, Division of Materials Sciences and Division of Chemical Sciences, under Contract No. DE-AC02-98CH10886. This work also received support from the US Department of Energy under grant number DEFG0397ER14749.

\section{REFERENCES}

Allada, R.K., Navrotsky, A., Berbeco, H.T. and Casey, W.H. (2002) Thermochemistry and aqueous solubilities of hydrotalcite-like solids. Science, 296, 721-723.

Allada, R.K., Navrotsky, A. and Boerio-Goates, J. (2005) Thermochemistry of hydrotalcite-like phases in the MgO$\mathrm{Al}_{2} \mathrm{O}_{3}-\mathrm{CO}_{2}-\mathrm{H}_{2} \mathrm{O}$ system: A determination of enthalpy, entropy, and free energy of hydrotalcite-like solids. American Mineralogist, 90, 329-355.

Allada, R.K., Peltier, E., Navrotsky, A., Casey, W.H., Johnson, A., Thompson-Berbeco, H. and Sparks, D.L. (2006) Calorimetric determination of the enthalpies of formation of hydrotalcite-like solids and their use in the geochemical modeling of metals in natural waters. Clays and Clay Minerals (in press).

Allison, J.D., Brown, D.S. and Novo-Gradac, K.J. (1991) MINTEQA2/PRODEFA2, a geochemical assessment model for environmental systems. U.S. Environmental Protection Agency.

Bellotto, M., Rebours, B., Clause, O., Lynch, J., Bazin, D. and Elkaim, E. (1996) A reexamination of hydrotalcite crystal chemistry. Journal of Physical Chemistry, 100, 8527-8534.

Bourrié, G., Trolard, F., Refait, P. and Feder, F. (2004) A solid-solution model for $\mathrm{Fe}(\mathrm{II})-\mathrm{Fe}(\mathrm{III})-\mathrm{Mg}$ (II) green rusts and fougerite and estimation of their gibbs free energies of formation. Clays and Clay Minerals, 52, 382-394.

Bravo-Suárez, J.J., Páez-Mozo, E.A. and Oyama, S.T. (2004a) Models for the estimation of thermodynamic properties of layered double hydroxides: Application to the study of their anion exchange characteristics. Quimica Nova, 27, $574-581$.

Bravo-Suárez, J.J., Páez-Mozo, E.A. and Oyama, S.T. (2004b) Review of the synthesis of layered double hydroxides: A thermodynamic approach. Quimica Nova, 27, 601-614.

Brindley, G.W. (1980) Lattice parameters and compositional limits of mixed $\mathrm{Mg}, \mathrm{Al}$ hydroxy structures. Mineralogical Magazine, 43, 1047.

Brindley, G.W. and Kikkawa, S. (1979) A crystal-chemical study of $\mathrm{Mg}, \mathrm{Al}$ and $\mathrm{Ni}, \mathrm{Al}$ hydroxy-perchlorates and hydroxycarbonates. American Mineralogist, 64, 836-843.

Brindley, G.W. and Kikkawa, S. (1980) Thermal behavior of hydrotalcite and of anion-exchanged forms of hydrotalcite. Clays and Clay Minerals, 28, 87-91.

Cavani, F., Trifirò, F. and Vaccari, A. (1991) Hydrotalicte-like anion clays: Preparation, properties and applications. Catalysis Today, 11, 173-301.

Dähn, R., Scheidegger, A.M., Manceau, A., Schlegel, M.L., Baeyens, B., Bradbury, M.H. and Morales, M. (2002) Neoformation of $\mathrm{Ni}$ phyllosilicate upon $\mathrm{Ni}$ uptake on montmorillonite: A kinetics study by powder and polarized extended X-ray absorption fine structure spectroscopy. Geochimica et Cosmochimica Acta, 66, 2335-2347.

Decarreau, A. (1980) Crystallogénèse expérimentale des smectites magnésiennes: hectorite, stévensite. Bulletin de Mineralogie, 103, 579-590.

Decarreau, A., Bonnin, D., Badaut-Trauth, D., Couty, R. and Kaiser, P. (1987) Synthesis and crystallogenesis of ferric smectite by evolution of $\mathrm{Si}-\mathrm{Fe}$ coprecipitates in oxidizing conditions. Clay Minerals, 22, 207-223. 
Depège, C., El-Metouri, F.-Z., Forano, C., de Roy, A. and Dupuis, J. (1996) Polymerization of silicates in layered double hydroxides. Chemistry of Materials, 8, 952-960.

d'Espinose de la Caillerie, J.-B., Karmeree, M. and Clause, O. (1995) Impregnation of $\gamma$-alumina with $\mathrm{Ni}(\mathrm{II})$ or $\mathrm{Co}$ (II) ions at neutral $\mathrm{pH}$ : Hydrotalcite-type coprecipitate formation and characterization. Journal of the American Chemical Society, 117, 11471-11481

Ford, R.G. and Sparks, D.L. (2000) The nature of $\mathrm{Zn}$ precipitates formed in the presence of pyrophyllite. Environmental Science and Technology, 34, 2479-2483.

Ford, R.G., Scheinost, A.C., Scheckel, K.G. and Sparks, D.L. (1999) The link between clay mineral weathering and the stabilization of $\mathrm{Ni}$ surface precipitates. Environmental Science and Technology, 33, 3140-3144.

Ford, R.G., Scheinost, A.C. and Sparks, D.L. (2001) Frontiers in metal speciation/precipitation mechanisms on soil mineral surfaces. Advances in Agronomy, 74, 41-62.

Génin, J.-M., Refait, P., Bourrié, G., Abdelmoula, M. and Trolard, F. (2001) Structure and stability of the Fe(II)$\mathrm{Fe}$ (III) green rust 'fougerite' mineral and its potential for reducing pollutants in soil solutions. Applied Geochemistry, 16, 559-570.

Gustafsson, J.P. (2004) Visual MINTEQ v 2.30. Swedish Royal Institute of Technology (KTH)

Hummel, W. and Curti, E. (2003) Nickel aqueous speciation and solubility at ambient conditions: a thermodynamic elegy. Monatshefte für Chemie, 134, 941-973.

Johnson, C.A. and Glasser, F.P. (2003) Hydrotalcite-like minerals $\left(M_{2} \mathrm{Al}(\mathrm{OH})_{6}\left(\mathrm{CO}_{3}\right)_{0.5} \cdot \mathrm{XH}_{2} \mathrm{O}\right.$ where $M=\mathrm{Mg}, \mathrm{Zn}, \mathrm{Co}, \mathrm{Ni})$ in the environment: synthesis, characterization and thermodynamic stability. Clays and Clay Minerals, 51, 1-8.

Kloprogge, J.T., Hickey, L. and Frost, R.L. (2001) Heating stage Raman and infrared emission spectroscopic study of the dehydroxylation of synthetic Mg-hydrotalcite. Applied Clay Science, 18, 37-49.

Lindsay, W.L. and Ajwa, H.A. (1995) Use of MINTEQA2 in teaching soil chemistry. Pp. 219-239 in: Chemical Equilibrium Reaction Models (R.H. Loeppert, S. Goldberg and A.P. Schwab, editors). American Society of Agronomy, Madison, Wisconsin.

Manceau, A., Calas, G. and Decarreau, A. (1985) Nickelbearing clay minerals: 1 . Optical spectroscopic study of nickel crystal chemistry. Clay Minerals, 20, 367-387.

Miyata, S. (1975) The synthesis of hydrotalcite-like compounds and their structures and physico-chemical properties - I: The systems $\mathrm{Mg}^{2+}-\mathrm{Al}^{3+}-\mathrm{NO}_{3}^{-}, \mathrm{Mg}^{2+}-\mathrm{Al}^{3+}-\mathrm{Cl}^{-}, \mathrm{Mg}^{2+}$ $\mathrm{Al}^{3+}-\mathrm{ClO}_{4}^{-}, \mathrm{Ni}^{2+}-\mathrm{Al}^{3+}-\mathrm{Cl}^{-}$and $\mathrm{Zn}^{2+}-\mathrm{Al}^{3+}-\mathrm{Cl}^{-}$. Clays and Clay Minerals, 23, 369-375.

Miyata, S. (1983) Anion-exchange properties of hydrotalcitelike compounds. Clays and Clay Minerals, 31, 305-311.

Naumov, G.B., Ryzhenko, B.N. and Khodakovsky, I.L. (1974) Handbook of Thermodynamic Data. National Technical Information Service, Pb-226, 722/7GA. US Department of Commerce.

Navrotsky, A. (1997) Progress and new directions in high temperature calorimetry revisited. Physics and Chemistry of Minerals, 24, 222-241.

Navrotsky, A., Rapp, R.P., Smelik, E., Burnley, P., Corcone, S., Chai, L. and Bose, K. (1994) The behavior of $\mathrm{H}_{2} \mathrm{O}$ and $\mathrm{CO}_{2}$ in high-temperature lead borate solution calorimetry of volatile-bearing phases. American Mineralogist, $\mathbf{7 9}$ 1099-1109.

O’Day, P.A., Parks, G.A. and Brown, G.E. Jr. (1994) Molecular-structure and binding-sites of cobalt(II) surface complexes on kaolinite from X-ray absorption spectroscopy.
Clays and Clay Minerals, 42, 337-355.

Pausch, I., Lohse, H.-H., Schürmann, K. and Allmann, R. (1986) Synthesis of disordered and Al-rich hydrotalcite-like compounds. Clays and Clay Minerals, 34, 507-510.

Reichle, W.T. (1986) Synthesis of anionic clay minerals (mixed metal hydroxides, hydrotalcite). Solid State Ionics, 22, 135-141.

Ressler, T. (1998) WinXAS: a program for X-ray absorption spectroscopy data analysis under MS-Windows. Journal of Synchrotron Radiation, 5, 118-122.

Roberts, D.R., Ford, R.G. and Sparks, D.L. (2003) Kinetics and mechanisms of $\mathrm{Zn}$ complexation on metal oxides using EXAFS spectroscopy. Journal of Colloid and Interface Science, 263, 364-376.

Robie, R.A. and Hemingway, B.S. (1995) Thermodynamic properties of minerals and related substances at $298.15 \mathrm{~K}$ and 1 Bar $\left(10^{5}\right.$ Pascals $)$ pressure and at higher temperatures. US Geological Survey Bulletin, 2131.

Rossini, F.D., Wagman, D.D., Evans, W.H., Levine, S. and Jaffe, I. (1952) Selected values of chemical thermodynamic properties. Circular of the National Bureau of Standards 500. US Government Printing Office.

Scheckel, K.G. and Sparks, D.L. (2001) Dissolution kinetics of nickel surface precipitates on clay mineral and oxide surfaces. Soil Science Society of America Journal, 65, 685-694.

Scheckel, K.G., Scheinost, A.C., Ford, R.G. and Sparks, D.L. (2000) Stability of layered Ni hydroxide surface precipitates - A dissolution kinetics study. Geochimica et Cosmochimica Acta, 64, 2727-2735.

Scheidegger, A.M., Lamble, G. and Sparks, D.L. (1997) Spectroscopic evidence for the formation of mixed-cation hydroxide phases upon metal sorption on clays and aluminum oxides. Journal of Colloid and Interface Science, 186, 118-128.

Scheidegger, A.M., Strawn, D.G., Lamble, G. and Sparks, D.L. (1998) The kinetics of mixed Ni-Al hydroxide formation on clay and aluminum oxide minerals: A time-resolved XAFS study. Geochimica et Cosmochimica Acta, 62, 2233-2245.

Scheinost, A.C. and Sparks, D.L. (2000) Formation of layered single and double metal hydroxide precipitates at the mineral/water interface: A multiple-scattering XAFS analysis. Journal of Colloid and Interface Science, 223, 167-178.

Tang, J. and Johannesson, K.H. (2003) Speciation of rare earth elements in natural terrestrial waters: Assessing the role of dissolved organic matter from the modeling approach. Geochimica et Cosmochimica Acta, 67, 2321-2339.

Taylor, R.M. (1984) The rapid formation of crystalline double hydroxy salts and other compounds by controlled hydrolysis. Clay Minerals, 19, 591-603.

Thompson, H.A., Parks, G.A. and Brown, G.E. (1999a) Ambient-temperature synthesis, evolution, and characterization of cobalt-aluminum hydrotalcite-like solids. Clays and Clay Minerals, 47, 425-438.

Thompson, H.A., Parks, G.A. and Brown, G.E. (1999b) Dynamic interactions of dissolution, surface adsorption and precipitation in an aging cobalt(II)-clay-water system. Geochimica et Cosmochimica Acta, 63, 1767-1779.

Towle, S.N., Bargar, J.R., Brown, G.E., Jr. and Parks, G.A. (1997) Surface precipitation of $\mathrm{Co}(\mathrm{II})(\mathrm{aq})$ on $\mathrm{Al}_{2} \mathrm{O}_{3}$. Journal of Colloid and Interface Science, 187, 62-68.

Zabinsky, S.I., Rehr, J.J., Ankudinoc, A., Albers, R.C. and Eller, M.J. (1995) Multiple scattering calculations of X-ray absorption spectra. Physics Review B, 52, 2995.

(Received 15 March 2005; revised 31 October 2005; Ms. 1028; A.E. James E. Amonette 
Table S1. Enthalpies and free energies of formation at $298.15 \mathrm{~K}$ and 1 bar of binary Ni compounds used in calculating $\Delta \mathrm{H}_{\mathrm{f}}^{\text {scc }}$ and $\Delta \mathrm{G}_{\mathrm{f}}^{\mathrm{scc}}$.

\begin{tabular}{|c|c|c|c|}
\hline Sample & $\Delta H_{\mathrm{f}}^{0}(\mathrm{~kJ} / \mathrm{mol})$ & $\Delta G_{\mathrm{f}}^{0}(\mathrm{~kJ} / \mathrm{mol})$ & Reference \\
\hline $\mathrm{Ni}(\mathrm{OH})_{2}$ & -540.3 & -459.1 & (Allada et al., 2006) \\
\hline $\mathrm{Ni}\left(\mathrm{NO}_{3}\right)_{2}$ & -427.6 & -236.0 & (Rossini et al., 1952) \\
\hline $\mathrm{NiSO}_{4}$ & -873.2 & -762.7 & (Robie and Hemingway, 1995) \\
\hline $\mathrm{NiCO}_{3}$ & -689.1 & -612.1 & (Naumov et al., 1974) \\
\hline $\mathrm{Ni}_{2} \mathrm{SiO}_{4}$ & -1390 & -1281 & (Robie and Hemingway, 1995) \\
\hline $\mathrm{Al}(\mathrm{OH})_{3}$ & -1293 & -1155 & (Robie and Hemingway, 1995) \\
\hline $\mathrm{H}_{2} \mathrm{O}$ & -285.8 & -237.1 & (Robie and Hemingway, 1995) \\
\hline $\mathrm{Ni}\left(\mathrm{NO}_{3}\right) * 6 \mathrm{H}_{2} \mathrm{O}$ & -2213 & & (Rossini et al., 1952) \\
\hline $\mathrm{NiSO}_{4} * 6 \mathrm{H}_{2} \mathrm{O}$ & -2683 & & (Robie and Hemingway, 1995) \\
\hline
\end{tabular}

Table S2. Free energies of formation at $298.15 \mathrm{~K}$ and 1 bar for aqueous species used to calculate solubility product constants for LDH phases. (Robie and Hemingway, 1995).

\begin{tabular}{lc}
\hline Species & $\Delta G_{\mathrm{f}, 298}^{0}$ \\
\hline $\mathrm{Ni}^{2+}$ & -45.6 \\
$\mathrm{Al}^{3+}$ & -489.4 \\
$\mathrm{CO}_{3}^{2-}$ & -527.9 \\
$\mathrm{SO}_{4}^{2-}$ & -744.6 \\
$\mathrm{NO}_{3}^{-}$ & -111.5 \\
$\mathrm{H}_{4} \mathrm{SiO}_{4}$ & -1308 \\
$\mathrm{H}_{2} \mathrm{O}$ & -237.2 \\
\hline
\end{tabular}

